\title{
Derechos humanos y responsabilidad social corporativa en las empresas de transporte. Un apunte de Derecho europeo
}

\author{
Human Rights and Corporate Social Responsibility in Transport \\ Companies. A Note on European Law
}

\author{
Unai Belintxon Martin \\ Profesor Contratado Doctor de Derecho Internacional Privado \\ Universidad Pública de Navarra \\ unai.belintxon@unavarra.es
}

\begin{abstract}
Sumario: I. Contextualización.-II. Derecho social europeo y transporte por carretera. Una referencia expresa a los DDHH, al descanso en cabina y a la honorabilidad de la empresa transportista. 1. El descanso ejecutado en la cabina del camión y la dignidad humana en el trabajo: ¿racionalización frente a nacionalismo jurídico? 2. Sobre foros exorbitantes, honorabilidad de la empresa transportista y vulneración de la tutela judicial efectiva, el derecho al juez predeterminado por la ley y la buena administración de justicia en la UE de los DDHH.-III. Derecho social europeo y el sector del transporte aéreo. 1. Contextualización. 2. Los tiempos de trabajo y descanso en el sector aéreo. ¿Un sector olvidado o descuidado por la persona legisladora? - IV. Consideración final.
\end{abstract}

Resumen: Este estudio tiene por objeto el análisis y la valoración crítica de la evolución jurídico-normativa experimentada en el ámbito de los Derechos Humanos y la responsabilidad social corporativa en las empresas de transporte en la UE. En particular el análisis centrará su atención en el sector del transporte internacional por carretera y en el sector del transporte aéreo internacional. Se estudiará y valorará si la UE de los derechos humanos del siglo XXI debe actuar de forma mucho más activa con el fin de evitar la fragmentación del proyecto europeo y el mercado interior, o si por el contrario debe mantener una actitud de inacción legislativa que permita a los Estados miembros de la UE seguir vulnerando el derecho europeo e incluso los derechos humanos en el sector del transporte.

Palabras clave: Derechos Humanos, Derecho internacional privado y derecho europeo, responsabilidad social corporativa en las empresas de transporte, transporte internacional por carretera.

Abstract: This study aims to analyse and critically assess the legal and regulatory developments in the field of Human Rights corporate social 
responsibility in transport companies in the EU. In particular the analysis will be focused on the study of the international road transport sector and the international air transport sector. It will consider and assess whether the EU of human rights in the 21 st century should act much more actively in order to avoid fragmentation of the European project and the internal market, or whether it should instead maintain an attitude of legislative inaction that allows EU Member States to continue to violate European law and even human rights in the transport sector.

Keywords: Human rights, international private Law and European Law, corporate social responsibility in transport companies, international carriage by road.

\section{Contextualización}

Desde luego conjugar una materia tan especializada ${ }^{1}$ como el Derecho del transporte en sus distintas modalidades con los Derechos Humanos y la responsabilidad social corporativa en las empresas de transporte supone un reto evidente ante la ausencia de concretos estudios doctrinales en la materia. Además, téngase en cuenta que esta aproximación de estudio y reflexión requiere de un enfoque o perspectiva caleidoscópica, o cuanto menos, multidisciplinar ${ }^{2}$, sin desatender la vertiente iusprivatista e internacional-privatista propia de nuestra disciplina y los distintos bloques normativos a analizar ${ }^{3}$.

Parte de la doctrina mercantilista e internacional-privatista ${ }^{4}$ viene de un tiempo a esta parte reclamando la especificidad y autonomía científica propia o inherente a este ámbito de estudio, pues la disciplina del Derecho

${ }^{1}$ Respecto a la especialización del Derecho privado en su vertiente internacional y europea, puede verse la esencial aportación reflexiva de: Julio Diego González Campos, «Diversification, Specialisation, Flexibilisation et Materialisation de régles de Droit International Privé», en R.des $C$, t. 287 (2002):156 y ss.

${ }^{2}$ Entre otros, sobre la cuestión: Cécile Legros, «Contrat de transport international par route de marchandises et de voyageurs», en Juris régles.Clas.dr.int, fasc. 571-66 (2012): 13 y ss.

3 Juan José Álvarez Rubio, «La regla de especificidad como cauce para superar los conflictos normativos entre Derecho comunitario y los Convenios internacionales en materias especiales», en La Ley, (29/10/2010): 1-6.

${ }^{4}$ Puede verse en relación con la particularidad del Derecho del transporte, las consideraciones realizadas por el profesor José Luis Iriarte Ángel, El contrato de embarque internacional, Beramar S.L., Madrid, (1993): 100 y ss. 
del transporte internacional (europeo y extra-europeo ${ }^{5}$ ) y nacional tiene suficiente entidad propia como para ser considerada autónoma respecto a las restantes disciplinas o áreas del Derecho ${ }^{6}$.

Combinar los Derechos Humanos, la responsabilidad social corporativa y el Derecho del transporte requiere un ejercicio de delimitación previa ${ }^{7}$ que permita concretar de qué manera o qué subsector de la citada disciplina autónoma permite un trinomio compuesto por las citadas tres materias. Sin lugar a dudas el espacio donde debe quedar enmarcado este estudio de investigación es el ámbito del Derecho social europeo del transporte. Entiéndase por éste, al objeto simplemente de concretar los contornos del estudio, aquellas distorsiones que afloran, o pudieran aflorar relacionadas con las normas sociales europeas proyectables sobre el personal de vuelo y sus tiempos de vuelo y descanso en el sector aéreo internacional; y los tiempos de conducción, trabajo y descanso de las personas conductoras y auxiliares en el ámbito del transporte internacional por carretera.

La nota de internacionalidad de nuestra disciplina y su propensión ha-

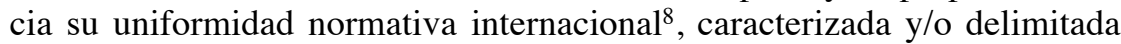
en la actualidad por el fenómeno de la europeización del Derecho privado ${ }^{9}$ con origen en el Tratado de Ámsterdam ${ }^{10}$, reforzada y consolidada en la actualidad tras diez años de vigencia del Tratado de Lisboa ${ }^{11}$, así como la pro-

${ }^{5}$ Respecto a la coexistencia de normas de Derecho uniforme internacional y Derecho nacional en la regulación de la responsabilidad contractual y extracontractual en el ámbito del Derecho marítimo, y la especificidad y complejidad de esta disciplina de estudio, entre otros, puede verse el trabajo monográfico dedicado al practicaje del profesor Iñaki Zurutuza Arigita, El Practicaje, Marcial Pons, Madrid, (2013): 225-299.

6 Marc Pichars, «L'évolution de la norme dans les transports», en Peru-Pirotte, L., Dupont-Legrand, B., y Landsweerdt, C. (Dirs.), Le Droit du transport dans tous ses états: réalités, enjeux et perspectives nationales, internationals et européennes, Larcier, Bruselas, (2012): 17-48.

7 En este sentido, entre otros: Unai Belintxon Martín, Derecho europeo y transporte internacional por carretera, Aranzadi, Cizur Menor, (2015): 42-49.

${ }^{8}$ Francesco Berlingieri, «Uniformité du Droit Maritime. Quelques problems», Il dir.mar, (1992-III): 796 y ss.; sobre el particular vid. igualmente Jan Ramberg, «Unification of transport law: difficulties and possibilities»,Dir.mar., (2010): 813-818. En relación a la historia de las Reglas de Rotterdam, vid. Francesco Berlingieri, «The history of the Rotterdam Rules», The United nations Convention on Contracts for the International Carriage of goods Wholly or Partly by Sea-An Appraisal of the Rotterdam rules, M.D. Guner-Özbek (Ed.), SpringerVerlag, Berlin-Heiderberg, (2011):1-63.

9 José Luis Iriarte Ângel, «La armonización del Derecho internacional privado por la Unión Europea», Jado: Boletín de la Academia Vasca del Derecho, n. ${ }^{\circ}$ 9, (2006): 47-73

${ }^{10}$ En este sentido vid. Alfonso Luis Calvo Caravaca, «El Derecho internacional privado de la Comunidad Europea», Anales de Derecho, Universidad de Murcia, n. ${ }^{\circ}$ 21, (2003): 49-69.

11 Juan José Álvarez Rubio, «La incidencia del Tratado de Ámsterdam en el sistema español de Derecho interregional», Anales de la Facultad de Derecho, 18, (noviembre de 2001): 65-78. 
yección o dimensión externa ${ }^{12}$ de este proceso $^{13}$, refleja de forma nítida una problemática específica, y es que dicho proyecto europeo ${ }^{14}$ vive momentos sombríos tras la salida de nuestros ex conciudadanos británicos ${ }^{15}$ y esto incide significativamente en la seguridad jurídica y en la previsibilidad de resultado $^{16}$, requiriendo para los que nos quedamos de un nuevo tiempo en la realidad internacional que pivote sobre una mayor integración ${ }^{17}$ y el fortalecimiento de las bases de un proyecto común ${ }^{18}$, el europeo, que se activó hace ya 63 años con el Tratado de Roma de $1957^{19}$.

El sector del transporte en todas sus modalidades constituye sin atisbo de duda el elemento vertebrador del desarrollo económico y social que garantiza la libertad de movilidad y libre circulación de personas y mercancías en una sociedad de naciones como es la Unión Europea ${ }^{20}$.

12 Alegría Borras Rodríguez, «La proyección externa de la comunitarización del Derecho internacional privado: los datos del problema», en La Ley, núm. 5611, (2002): 1-8.

13 Véase Alegría Borras Rodríguez, «La Comunitarización del Derecho Internacional Privado: pasado, presente y futuro», Cursos de Derecho Internacional de Vitoria-Gasteiz. (2001), Vitoria-Gasteiz, Servicio de Publicaciones de la Universidad del País Vasco, (2002): 285-318; Mónica Guzmán Zapater, «Cooperación civil y Tratado de Lisboa: ¿Cuánto hay de nuevo?», La Ley, n. ${ }^{\circ} 7479$, (2010): 713 y ss.

${ }^{14}$ En este sentido vid: José Carlos Fernández Rozas, «La comunitarización del Derecho internacional privado y Derecho aplicable a las obligaciones contractuales», $R E S, \mathrm{n} .{ }^{\circ} 140$, (2009): 600 y ss.

${ }_{15}$ Una realidad a la que se enfrenta hoy el legislador europeo. Sobre esta cuestión, entre otros: Sara Moya Izquierdo, Clara García Fernández y Miguel Troncoso Ferrer, «El posible impacto del Brexit en los contratos internacionales de ámbito europeo», en Revista Aranzadi Unión Europea, núm. 12, (2016).

${ }^{16}$ Sobre la evolución jurídica en el espacio europeo del Derecho internacional, entre otros: Pedro A. de Miguel Asensio, «Integración Europea y Derecho Internacional Privado», RDCE, vol. 2, (1997): 413-445.

17 En relación a la integración económica y el desarrollo de un nivel adecuado de coordinación jurídica puede verse entre otros estudios José María Gondra Romero, «Integración económica e integración jurídica en el marco de la Comunidad Económica Europea», en García De Enterría, E., González Campos J.D., Muñoz Machado S., (Dirs.), Tratado de Derecho comunitario europeo, vol. I, Madrid, (1986): 275-312.

18 Juan José Álvarez Rubio, «Transporte Marítimo Internacional de Mercancías: alcance material y conflictual de la Autonomía Contractual», en III Seminario internacional de Derecho Internacional Privado: Autorregulación y unificación del derecho de los contratos internacionales, Universidad Complutense de Madrid, (2009): 558-559.

19 José Carlos Fernández Rozas, «El 60 aniversario de los Tratados de Roma: algo más que una simple celebración», La Ley, 46, (2017): 1-8.

${ }^{20}$ Sobre la legislación laboral aplicable a los trabajadores desplazados en relación a una prestación de servicios, puede verse el exhaustivo estudio de la profesora Marta Casado Abarquero, «Legislación aplicable a los trabajadores desplazados en el marco de una prestación de servicios en la Unión Europea», Goñi Sein, J.L, e Iriarte Ángel, J.L. (Dirs), Prevención de riesgos laborales y protección social de trabajadores expatriados, Thomson Reuters Aranzadi, Cizur Menoz, (2019): 339-369. 
Este complejo ensamblaje jurídico-social no se mantiene sin personas empleadas ni personas empleadoras a las que se debe garantizar la dignidad humana en el trabajo como elemento nuclear de la Unión Europea de los Derechos Humanos para este siglo XXI.

En efecto, la distinta interpretación de las normas europeas y nacionales de aplicación al ámbito de estudio genera cierto estado de inseguridad jurídica e inquietud ${ }^{21}$ que lastima el habitual desarrollo del estado de las cosas y que parece deslegitima en parte nuestro proyecto europeo ${ }^{22}$. No obstante, el camino a seguir es avanzar y reducir exponencialmente las distorsiones producidas por una interpretación des-armonizada de las normas europeas ${ }^{23}$ y de los estándares para los Derechos Humanos en el Derecho internacional.

Avanzar en materia de armonización del Derecho social europeo de los Derechos Humanos mediante normas eficaces y efectivas que posibiliten un mejor y mayor control de las condiciones y de los tiempos de trabajo y descanso en el ámbito aéreo y/o rodado posibilitaría fortalecer la política de transportes común de la Unión Europea ${ }^{24}$ junto a la seguridad ${ }^{25}$ y reducir exponencialmente las distorsiones ocasionadas por una lectura interpretativa restrictiva o contraria al carácter armonizador de las normas de la Unión Europea ${ }^{26}$. La sentencia del TJCE de 22 de mayo del año $1985^{27}$ dejó claramente identificado y delimitado que el estancamiento de una política

${ }^{21}$ Entre otros sobre la cuestión: Rafael Caballero Sánchez, «La liberalización del transporte terrestre: el largo camino hacia un mercado de servicios», en Menéndez, P. (Dir.), Régimen Jurídico del Transporte Terrestre: Carreteras y Ferrocarril, Tomo I, Aranzadi, Cizur Menor, (2014): 397-488.

22 José Luis Iriarte Ángel, «Conflictos de leyes internos. Notas fundamentales de la situación actual», Jado: boletín de la Academia Vasca del Derecho, núm. 18, (diciembre de 2009): 55-93.

23 Juan José Álvarez Rubio, «Derecho privado y la UE: ¿armonización material o conflictual?», en Goizueta Vértiz, J., y Cinfuegos Mateo, M., La eficacia de los derechos fundamentales de la UE: cuestiones avanzadas, Thomson Reuters Aranzadi, Cizur Menor, (2014): 291-310.

${ }^{24}$ M.A. Guzmán Gómez, «La aplicación en España de la política común de transportes», en $D A$, núm. 201, (1984): 675-706.

25 Calos Muñoz-Repiso Izaguirre, «Políticas de seguridad en el transporte por carretera», en Noticias de la Unión Europea, núm. 246, (2005): 33-39.

${ }^{26}$ En relación a la diversidad de fuentes y a la tendencia actual hacia la armonización de las normas aplicables al sector del Derecho del transporte, puede verse entre otros: Isabel Bon Garcín, Maurice Bernadet e Yves Reinhard, Droit des transports, Dalloz, Paris, (2010): 2 y ss.

27 Sentencia del Tribunal de Justicia de 22/05/1985, en el asunto 13/83 entre el Parlamento Europeo, apoyado por la Comisión de las Comunidades Europeas, contra el Consejo de las Comunidades Europeas, apoyado por el Reino de los Países Bajos, y que tuvo por objeto un recurso interpuesto con arreglo al artículo 175 del Tratado CEE con el fin de que se declarase la omisión del Consejo en materia de política común de transportes. 
común de transportes europea ${ }^{28}$ viene propiciado por los distintos, importantes y contrapuestos intereses estatales en conflicto ${ }^{29}$.

\section{Derecho social europeo y transporte por carrera. Una referencia expresa a los DDHH, al descanso en cabina y a la honorabilidad de la empresa transportista}

\section{El descanso ejecutado en la cabina del camión y la dignidad humana en el trabajo: ¿racionalización frente a nacionalismo jurídico?}

Para este concreto sector debe reconocerse que la legisladora y el legislador de la UE han trabajado con un proceder constante y continuo para posibilitar un ensamblaje normativo que aglutine distintas cuestiones que afectan a las trabajadoras y trabajadores del sector. El Acuerdo europeo relativo al trabajo de los conductores de vehículos que efectúan transportes internacionales por carretera (AETR) de 1969, impulsado por la OIT ${ }^{30}$, que no obvia los criterios hermenéuticos establecidos por el Convenio de Roma de 1950 y el TEDH, representa la base originaria de un marco integrado y consolidado en la actualidad mediante la coexistencia de diferentes normas ${ }^{31}$.

28 Sobre la política común de transportes en la UE, puede verse a Francesco Munari, $I l$ Diritto Comunitario dei Trasportti, Guiffrè, Milán, (1996): 50-117.

29 Sobre la sentencia citada del Tribunal de Justicia, pueden verse entre otras las reflexiones realizadas por Marta Arpio Santa Cruz, «El Parlamento frente al Consejo: la sentencia del Tribunal de Justicia en materia de transportes», en RIE, núm. 12, (1985): 789-804.

30 BOE núm. 277, de 18/11/1976.

31 Directiva 2002/15/CE del Parlamento Europeo y del Consejo de 11 de marzo de 2002 relativa a la ordenación del tiempo de trabajo de las personas que realizan actividades móviles de transporte por carretera -DOUE L 80/35 de 23/03/2002 - , el Reglamento 561/2006 del Parlamento Europeo y del Consejo de 15 de marzo de 2006 relativo a la armonización de determinadas disposiciones en materia social en el sector de los transportes por carretera -DOUE L 102/1 de 11/04/2006 - , la Directiva 2003/59/CE del Parlamento Europeo y del Consejo de 15 de julio de 2003 relativa a la cualificación inicial y la formación continua de los conductores de determinados vehículos destinados al transporte de mercancías o de viajeros por carretera - DOUE L 226/4 de 10/09/2003 - , la Directiva 2006/22/CE del Parlamento Europeo y del Consejo de 15 de marzo de 2006 sobre las condiciones mínimas para la aplicación de los Reglamentos del Consejo (CEE) núm. 3820/85 y (CEE) núm. 3821/85 en lo que respecta a la legislación social relativa a las actividades de transporte por carretera -L 102/35 de 11/04/2006-, el Reglamento (CE) núm. 1073/2009 del Parlamento Europeo y del Consejo de 21 de octubre de 2009 por el que se establecen normas comunes de acceso al mercado internacional de los servicios de autocares y autobuses y por el que se modifica el Reglamento (CE) núm. 561/2006 -DOUE L 300/88 de 14/11/2009-, y con el Reglamento (UE) núm. 165/2014 del Parlamento Europeo y del Consejo de 4 de febrero de 2014 relativo a los tacógrafos en el transporte por carretera - DOUE L 60/1 de 28/02/2014-. 
De todas ellas cabe resaltar en materia de tiempos de descanso el Reglamento (CE) 561/2006 de 15 de marzo de 2006. Una norma que combina normas de regulación ${ }^{32}$ con normas de ordenación administrativa y laboral $^{33}$. El TJUE se ha pronunciado en diversas ocasiones sobre la interpretación de las normas contenidas en el citado texto normativo. Un texto que ha permitido distintas interpretaciones interesadas por parte de los diferentes Estados miembros de la UE en lo que respecta a la forma de articular los tiempos de descanso tras la jornada de trabajo y conducción correspondiente ${ }^{34}$.

Ante unas instituciones y una UE que no afrontan la obligada mutación hacia una integración plena en una sociedad de naciones (llámese los Estados Unidos de Europa), en detrimento de su liquidación o progresiva dilución, las diferencias socio-económicas y culturales (junto a la inacabada materialización de la apertura y la supresión de las barreras interiores en el mercado único ${ }^{35}$ ) se han acrecentado de forma exponencial creando inercias, que no sinergias, y protectorados nacionales internos a golpe de legislar sin mesura bordeando, cuando no claramente contraviniendo, la legalidad europea. Así, es bien conocida la denominada LOI $n .^{o} 2015-990$ du 6 août 2015 pour la croissance, l'activité et l'égalité des chances économiques francesa ${ }^{36}$, que en su cardinal 280 viene, entre otras cuestiones, a normativizar o positivizar la imposibilidad de ejecutar los descansos semanales reducidos en el habitáculo condicionado al efecto en

32 Respecto a la evolución de la ordenación administrativa en el sector del transporte por carretera véase, Marcos Gómez Puente, «La ordenación histórica del transporte por carretera», en Menéndez P. (Dir.), Régimen Jurídico del Transporte Terrestre: Carreteras y Ferrocarril, Tomo I, Aranzadi, Cizur Menor, (2014):167-189.

33 Sobre ordenación administrativa e intervención en el sector del transporte, entre otros, puede verse: Carmen Agoués Mendizabal, «La intervención administrativa en el transporte por carretera», en $R D T$, núm. 7,( 2011): 51-92.

${ }^{34}$ Sobre la materia, entre otros: Francisco Trujillo Pons, «La regulación del tiempo de trabajo en el transporte por carretera en la normativa comunitaria y su trasposición al ordenamiento jurídico español», en Petit Lavall, M. ${ }^{a}$.V., Martínez Sanz, F., y Recaldes Castells, A. (Dirs.), La nueva ordenación del mercando de transporte, Marcial Pons, Madrid, (2013): 6784; Alfonso Sánchez Marcos, «El tacógrafo digital: sistema de seguridad y control de vehículos para transporte de viajeros y mercancías», en Actualidad Jurídica del transporte por carretera, Fundación Francisco Corell, Madrid, (2005):105-109.

35 Respecto a la supresión de las barreras nacionales al comercio internacional y la discriminación por razón de la nacionalidad en la actividad comercial puede verse: José Carlos Fernández Rozas, Sistema de Derecho económico internacional, Thomson Civitas, Cizur Menor, (2010): 55 y ss.

36 Journal Officiel de la République Française, 07/08/2015, Texte 1 sur 115, www.legifrance.gouv.fr. 
la propia tractora del vehículo pesado ${ }^{37}$. En efecto, no es posible, o por lo menos es perseguible administrativa y penalmente en dicho país realizar los tiempos de descanso preceptivos en un camión para el que se ha abonado un sobrecoste en el precio al fabricante por parte del empresario porteador. Y todo ello vulnerando la legalidad europea, pues el artículo 8.8 del citado Reglamento (CE) 561/2006 permite que cuando el conductor elija hacerlo, los períodos de descanso diarios y los períodos de descanso semanales reducidos tomados fuera del centro de explotación de la empresa puedan efectuarse en el vehículo siempre y cuando éste vaya, adecuadamente equipado para el descanso de cada uno de los conductores y esté estacionado ${ }^{38}$.

El país vecino argumenta para justificar su clara vulneración del Derecho europeo que la finalidad de su norma interna es permitir verificar por parte de la autoridad pública «des conditions de travail ou d'hébergement incompatibles avec la dignité humaine. En esencia, estima la legisladora y/o el legislador francés que la materialización del descanso en el habitáculo, o litera de la cabina tractora ${ }^{39}$, del vehículo pesado es contrario a la dignidad humana al ser una condición de trabajo incompatible con ésta y con los Derechos Humanos. La comisión de tal fechoría por la persona empresaria porteadora o transportista según lo preceptuado en el artículo 225-14 del Code pénal francés está penada con pena privativa de libertad de hasta 5 años de cárcel y 150000 euros de multa.

No obstante, expuesto lo anterior cabe recordar que el TJUE ya interpretó muy acertadamente el artículo 8.8 del Reglamento en su sentencia de 20 de diciembre de $2017^{40}$. En efecto, el Tribunal concluyó adecuadamente (apartado 23), a pesar de los intentos a sensu contrario de los Estados Belga, Alemán, Austriaco y Francés, que los periodos de descanso diarios y los periodos de descanso semanales reducidos (aquellos inferiores a 45 horas consecutivas de descanso) pueden tomarse en vehículo debidamente equipado para ello. No así los periodos de des-

37 Unai Belintxon Martín, «Dumping Social, desarmonización socio-laboral y Derecho internacional privado: la des-Unión Europea», en AEDIPr, t. XVI, (2016): 611-642.

${ }^{38}$ Respecto a esta cuestión, aunque con otro enfoque, puede verse: Unai Belintxon Martín, «Prevención de riesgos laborales, transporte y derecho europeo: distorsiones de la realidad práctica», La Ley Unión Europea, n. ${ }^{\circ} 73$, (2019): 1-19.

39 Sobre la existencia de otros mecanismos de protección de los trabajadores desplazados y en referencia otros sectores, entre otros puede verse: M. a del Carmen Vaquero López, «Mecanismos de Derecho Internacional Privado Europeo para la protección de los trabajadores en supuestos de deslocalización de empresas», en AEDIPr, núm. 17, (2017): 425-471.

40 STJUE de 20/12/2017, Asunto C-102/16, Vaditrans BVBA vs. Belgische Staat.ECLI: EU:C: 2017:1012. Aranzadi. 
canso semanales normales que deberán tomarse fuera del vehículo habilitado al efecto (es decir aquellos iguales o superiores a 45 horas consecutivas de descanso).

El mantenimiento de la conflictividad interpretativa y la vulneración del Derecho europeo por parte del Estado francés profiriendo una interpretación jurídico-normativa contraria, o a sensu contrario, a lo legislado por el parlamento europeo y el consejo, no hace sino acrecentar la inseguridad jurídica para las empresas operadores en el sector (cargadoras, usuarias, pasajeras, transportistas o porteadores contractuales, empresas de intermediación, agentes, comisionistas, y/o transportistas/porteadoras efectivas), la desconfianza en el seno de la UE y la constricción del comercio internacional en territorio común mermando con ello garantías nucleares como la libre prestación de servicios, la libre circulación ${ }^{41}$ y la confianza depositada en el espacio de libertad, seguridad y justicia diseñado y normativizado en el TFUE ${ }^{42}$.

Pero no es el único ámbito dentro de este complejo y apasionante sector en el que nuestro país vecino viene legislando en contra del sentido común y de la seguridad jurídica, la evitación de procedimientos paralelos, la buena administración de justicia y la garantía recíproca en la confianza en seno de la justicia en la UE.

2. Sobre foros exorbitantes, honorabilidad de la empresa transportista y vulneración de la tutela judicial efectiva, el derecho al juez predeterminado por la ley y la buena administración de justicia en la UE de los $\mathrm{DDHH}$

Por otro lado, y también en relación a la aplicación e interpretación del Reglamento 561/2006 sobre Derecho social europeo y tiempos de conducción, trabajo y descanso ${ }^{43}$ en el ámbito del transporte rodado por carretera el/la legislador/a francés/a se aventuró a interpretar y normativizar restrictivamente en su legislación interna, y en este caso, además, con flagrante

${ }^{41}$ Unai Belintxon Martin «La confluencia de los distintos bloques normativos aplicables en materia de transporte internacional por carretera: divergencias y efecto distorsionador», en Petit Lavall, M.V., Martínez Sanz, F., y Recalde Castells, A. (Dirs.), La nueva ordenación del mercado de transporte, Marcial Pons, Madrid, (2013): 15-20.

42 Sobre este particular véase: José Carlos Fernández Rozas, «El Espacio de libertad, seguridad y justicia consolidado por la Constitución Europea», en La Ley, D-195, (2004): 16.

${ }^{43}$ Puede verse sobre esta materia de descanso, las referencias realizadas a otros sectores del transporte por el profesor José Luis Iriarte Ángel, «La precisión del lugar habitual de trabajo como foro de competencia y punto de conexión en los Reglamentos europeos», en CDT, Vol.10, núm. 2, (Octubre de 2018): 488-495. 
vulneración de los artículos $6^{44}$ y $7^{45}$ de $\mathrm{CEDH}^{46}$ y de los artículos $47^{47}$ y $48^{48}$ de la Carta Europea de Derecho Fundamentales ${ }^{49}$ (ambos preceptos dedicados y garantes de la máxima expresión de la tutela judicial efectiva, el concepto de no pena sin ley y la buena administración de justicia ${ }^{50}$, que en

44 1. Toda persona tiene derecho a que su causa sea oída equitativa, públicamente y dentro de un plazo razonable, por un Tribunal independiente e imparcial, establecido por ley, que decidirá los litigios sobre sus derechos y obligaciones de carácter civil o sobre el fundamento de cualquier acusación en materia penal dirigida contra ella. La sentencia debe ser pronunciada públicamente, pero el acceso a la sala de audiencia puede ser prohibido a la prensa y al público durante la totalidad o parte del proceso en interés de la moralidad, del orden público o de la seguridad nacional en una sociedad democrática, cuando los intereses de los menores o la protección de la vida privada de las partes en el proceso así lo exijan o en la medida en que sea considerado estrictamente necesario por el tribunal, cuando en circunstancias especiales la publicidad pudiera ser perjudicial para los intereses de la justicia. 2. Toda persona acusada de una infracción se presume inocente hasta que su culpabilidad haya sido legalmente declarada. 3. Todo acusado tiene, como mínimo, los siguientes derechos: a) a ser informado, en el más breve plazo, en una lengua que comprenda y de manera detallada, de la naturaleza y de la causa de la acusación formulada contra él; b) a disponer del tiempo y de las facilidades necesarias para la preparación de su defensa; c) a defenderse por sí mismo o a ser asistido por un defensor de su elección y, si carece de medios para pagarlo, a poder ser asistido gratuitamente por un abogado de oficio, cuando los intereses de la justicia así lo exijan; d) a interrogar o hacer interrogar a los testigos que declaren en su contra y a obtener la citación e interrogatorio de los testigos que declaren en su favor en las mismas condiciones que los testigos que lo hagan en su contra; e) a ser asistido gratuitamente de un intérprete si no comprende o no habla la lengua empleada en la audiencia.

45 1. Nadie podrá ser condenado por una acción o una omisión que, en el momento en que haya sido cometida, no constituya una infracción según el derecho nacional o internacional. Igualmente, no podrá ser impuesta una pena más grave que la aplicable en el momento en que la infracción haya sido cometida.2. El presente artículo no impedirá el juicio o la condena de una persona culpable de una acción o de una omisión que, en el momento de su comisión, constituía delito según los principios generales del derecho reconocido por las naciones civilizadas.

46 BOE núm. 243, de 10 de octubre de 1979.

${ }^{47}$ Derecho a la tutela judicial efectiva y a un juez imparcial: Toda persona cuyos derechos y libertades garantizados por el Derecho de la Unión hayan sido violados tiene derecho a la tutela judicial efectiva respetando las condiciones establecidas en el presente artículo. Toda persona tiene derecho a que su causa sea oída equitativa y públicamente y dentro de un plazo razonable por un juez independiente e imparcial, establecido previamente por la ley. Toda persona podrá hacerse aconsejar, defender y representar. Se prestará asistencia jurídica gratuita a quienes no dispongan de recursos suficientes siempre y cuando dicha asistencia sea necesaria para garantizar la efectividad del acceso a la justicia.

${ }^{48}$ Presunción de inocencia y derechos de la defensa: 1. Todo acusado se presume inocente mientras su culpabilidad no haya sido declarada legalmente. 2. Se garantiza a todo acusado el respeto de los derechos de la defensa.

49 DOUE C 303 de 14 de diciembre de 2007.

50 Sobre el artículo 47 de la CDFUE, entre otros: Ciro Milione Fugali, La interpretación del art. 47 CDFUE como expresión de la labor hermenéutica del Tribunal de Luxemburgo en la construcción de un estándar europeo de protección de los derechos. Teoría y realidad constitu- 
materia de infracciones $\mathrm{y} / \mathrm{o}$ sanciones penales $\mathrm{y} / \mathrm{o}$ administrativas sometidas al citado Reglamento europeo, los autores o autoras y/o personas cómplices de dichos delitos e infracciones pueden ser procesadas y enjuiciadas, con independencia de que dichos delitos e infracciones hayan sido cometidos fuera del territorio de la República Francesa en materia de transporte internacional de mercancías y/o viajeros/as por carretera, por los tribunales franceses cuando, de conformidad con las disposiciones del Libro I del Código Penal o de cualquier otra ley, la ley francesa sea aplicable, o cuando un convenio internacional o un acto adoptado con arreglo al Tratado Constitutivo de la Comunidad Europea otorgue a los tribunales franceses jurisdicción para conocer del delito.

El artículo 36 de la LOI n. ${ }^{\circ} 2009-1503$ de 8 de diciembre de $2009^{51}$, en materia de infracciones nos remite al código penal francés y al código de procedimiento penal para esta cuestión ${ }^{52}$. Y concretamente, se posibilita en materia de transporte por carretera, aplicar el artículo 689 del Code de Procedure Pénale ${ }^{53}$ que recoge que,

Les auteurs ou complices d'infractions commises hors du territoire de la République peuvent être poursuivis et jugés par les juridictions

cional, n. ${ }^{\circ}$ 39, (Ejemplar dedicado a: Monográfico: El TJUE como actor de constitucionalidad), (2017): 655-674.

${ }^{51}$ LOI n ${ }^{\circ}$ 2009-1503 du 8 décembre 2009 relative à l'organisation et à la régulation des transports ferroviaires et portant diverses dispositions relatives aux transport, du 8 décembre 2009. https://www.legifrance.gouv.fr/affichTexte.do?cidTexte=JORFTEXT000021451610\&c ategorieLien=cid. (Última visita 15.02.2020).

52 I. - Après le deuxième alinéa de l'article 113-6 du code pénal, il est inséré un alinéa ainsi rédigé: «Elle est applicable aux infractions aux dispositions du règlement (CE) no 561/2006 du Parlement européen et du Conseil du 15 mars 2006 relatif à l'harmonisation de certaines dispositions de la législation sociale dans le domaine des transports par route, commises dans un autre Etat membre de l'Union européenne et constatées en France, sous réserve des dispositions de l'article 692 du code de procédure pénale ou de la justification d'une sanction administrative qui a été exécutée ou ne peut plus être mise à exécution». II. - A l'article 689 du code de procédure pénale, après les mots : «convention internationale», sont insérés les mots : «ou un acte pris en application du traité instituant les Communautés européennes». III. - Après l'article 689-10 du même code, il est inséré un article 689-12 ainsi rédigé: «Art. 689-12. - Pour l'application du règlement (CE) no 561/2006 du Parlement européen et du Conseil du 15 mars 2006 relatif à l'harmonisation de certaines dispositions de la législation sociale dans le domaine des transports par route, peut être poursuivie et jugée dans les conditions prévues à l'article 689-1 toute personne coupable d'infractions à la réglementation du temps de conduite et de repos au sens du chapitre II du même règlement commises dans un Etat de l'Union européenne».

${ }^{53} \mathrm{https}$ ://www.legifrance.gouv.fr/affichCodeArticle.do;jsessionid=457FBE75F2A60AB 5ECEFB0F711516927.tplgfr36s_1?cidTexte=LEGITEXT000006071154\&idArticle=LEGIA RTI000021486423\&dateTexte=20200216\&categorieLien=id\#LEGIARTI000021486423 . (última visita 15.02.2020). 
françaises soit lorsque, conformément aux dispositions du livre Ier du code pénal ou d'un autre texte législatif, la loi française est applicable, soit lorsqu'une convention internationale ou un acte pris en application du traité instituant les Communautés européennes donne compétence aux juridictions françaises pour connaître de l'infraction.

Desde luego, tales exorbitantes competencias jurisdiccionales estatales y criterios de atribución con base en un concepto de justicia universal e imperialismo jurídico, merman la seguridad jurídica que necesariamente demanda este peculiar sector del transporte y vulnera las citadas garantías contenidas en los artículos 6 y 7 del CEDH sobre tutela judicial efectiva, proceso justo y derecho al juez predeterminado por la ley. Recuérdese que el TEDH viene interpretando ampliamente, sin restricciones y sin permisión de excepcionalidad alguna el citado artículo 6 del CEDH. En relación a ello, el Tribunal Europeo llega a concluir y advertir expresamente, entre otras, en el apartado 30 de su sentencia de 26 de octubre de 1984, Cubber vs. Belgium ${ }^{54}$, que «una interpretación restrictiva del artículo 6.1 [...] no encajaría con el objeto y finalidad de esta disposición, visto el lugar eminente que el derecho a un proceso justo ocupa en una sociedad democrática, en el seno del Convenio [...]»

De igual forma y en esta línea interpretativa sobre el citado artículo 6 CEDH el Tribunal subraya en el apartado 66 de su sentencia de 23 de octubre de 1990, Moreira De Azevedo vs. Portugal ${ }^{55}$, que «In the Court's opinion, the right to a fair trial holds so prominent a place in a democratic society that there can be no justification for interpreting Article 6 para. 1 (art. 6-1) of the Convention restrictively».

En efecto, una atribución competencial injustificable de las autoridades francesas para conocer de cualquier infracción que se haya podido cometer respecto de cualquier transporte que circule por su territorio en base a los Reglamentos europeos que regulan el transporte internacional de mercancías y personas viajeras por carretera intraeuropeo en la Unión Europea y el acceso al mercado de transporte (Reglamentos 1071,1072 y 1073 del año $\left.2009^{56}\right)$.

${ }^{54}$ STEDH de 26 de octubre de 1984. Recuperada: https://hudoc.echr.coe.int/ spa\#\{"fulltext":["16 de octubre de 1984"],"documentcollectionid2":["GRANDCHAMBER", "CHAMBER"],"itemid":["001-165125"]\}. (Última visita. 15.02.2020).

55 STEDH de 23 de 10 de 1990. Recuperada: https://hudoc.echr.coe.int/ spa\#\{"fulltext":["Moreira de Azevedo c. Portugal"],"documentcollectionid2":["GRANDCHA MBER","CHAMBER"],"itemid":["001-57645"]\} . (Última visita. 15.02.2020).

56 Reglamento (CE) n. ${ }^{\circ}$ 1071/2009 del Parlamento Europeo y del Consejo, de 21 de octubre de 2009 , por el que se establecen las normas comunes relativas a las condiciones que han de cumplirse para el ejercicio de la profesión de transportista por carretera y por el que se 
No es la única ocasión en la que el país vecino se aventura con la articulación y proyección de foros calificables como exorbitantes en su legislación interna para la asunción de competencia en cuestiones jurisdiccionales de carácter penal, administrativo o civil. Para cuestiones de Derecho procesal civil internacional el artículo 14 del Code Civil francés viene a disponer que,

L'étranger, même non résidant en France, pourra être cité devant les tribunaux français, pour l'exécution des obligations par lui contractées en France avec un Français; il pourra être traduit devant les tribunaux de France, pour les obligations par lui contractées en pays étranger envers des Français.

Sin lugar a dudas la activación tras la asunción de la competencia por los tribunales franceses en las materias señaladas conllevaría el no reconocimiento y la inejecución de las respectivas resoluciones con sus sanciones y/o condenas en el resto de Estados miembros de la UE, calificándose dichos pronunciamientos judiciales como sentencias claudicantes.

En efecto, la derivada más alarmante de este nacionalismo jurídico inaceptable contrario al Derecho europeo, y como se ha podido analizar, contrario también a los Derechos Humanos, conlleva que ante una condena penal o sanción (penal y/o administrativa) en Francia de la empresa porteadora/transportista y/o las personas que ostenten la dirección y/o la gestión de la empresa, y siempre y cuando éstas ya estén retenidas por las autoridades públicas francesas y/o en prisión en Francia, a la luz del ordenamiento jurídico francés y en aplicación del artículo $10.3^{57}$ del Reglamento 561/2006, si fuera el caso, que recoge una suerte de responsabilidad objetiva del empresario por las infracciones cometidas por las personas subordinadas (conductoras y auxiliares) con independencia del Estado miembro donde hayan sido cometidas (y que refrenda y encuentra acomodo en la jurisprudencia del TJUE, entre otras, en su sentencia de 19 de octubre de

deroga la Directiva 96/26/CE del Consejo. DOUE L300/51 de 14.11.209; Reglamento (CE) n. ${ }^{\circ} 1072 / 2009$ del Parlamento Europeo y del Consejo, de 21 de octubre de 2009, por el que se establecen normas comunes de acceso al mercado del transporte internacional de mercancías por carretera. DOUE L 300/72 de 14.11.2009; Reglamento (CE) n. ${ }^{\circ}$ 1073/2009 del Parlamento Europeo y del Consejo, de 21 de octubre de 2009, por el que se establecen normas comunes de acceso al mercado internacional de los servicios de autocares y autobuses y por el que se modifica el Reglamento (CE) n..$^{\circ}$ 561/2006. DOUE L 300/88 de 14.11.2009.

57 Artículo 10.3: Las empresas de transporte tendrán responsabilidad por las infracciones cometidas por los conductores de esas empresas, aun cuando tales infracciones se hayan cometido en el territorio de otro Estado miembro o de un tercer país. 
$2016^{58}$ ), y del artículo $6^{59}$ del Reglamento (CE) 1071 del año 2009 sobre la precisión de las condiciones que han de respetarse por las empresas transportistas en materia de honorabilidad (inexistencia de condenas, sanciones y/o infracciones en materia mercantil, penal, socio-laboral, administrativa etc.) la citada empresa perderá la honorabilidad y con ello la licencia comunitaria que le habilita para ejercer la profesión de transportista por carretera en la UE.

Y esto supone el cierre o liquidación de dicha empresa por imposibilidad de continuar con la actividad propia de este específico sector del tejido empresarial sin autorización o título habilitante ${ }^{60}$ favoreciéndose con ello la destrucción de empleo, la desinversión y un menor progreso económico y social.

58 STJUE de 19 de octubre de 2016 (Asunto C-501/14, EL-EM-2001 vs. Nemzeti). Aranzadi.

59 Precisión de las condiciones que han de respetarse en materia de honorabilidad:1. Sin perjuicio de lo dispuesto en el apartado 2 del presente artículo, los Estados miembros determinarán las condiciones que deben cumplir las empresas y gestores de transporte a fin de cumplir el requisito de honorabilidad establecido en el artículo 3, apartado 1, letra b). Al determinar si una empresa cumple dicho requisito, los Estados miembros tomarán en consideración la conducta de la empresa, sus gestores de transporte y cualquier otra persona pertinente que pueda determinar el Estado miembro. Toda referencia que se haga en el presente artículo a condenas, sanciones o infracciones incluirá las condenas, sanciones o infracciones de la propia empresa, sus gestores de transporte y cualquier otra persona pertinente que pueda determinar el Estado miembro. Entre las condiciones mencionadas en el párrafo primero figurarán, como mínimo, las siguientes: a) que no exista ningún motivo importante para dudar de la honorabilidad del gestor de transporte o de la empresa de transporte, como la imposición de condenas o sanciones por cualquier infracción grave de la normativa nacional en vigor en los ámbitos de: i) el Derecho mercantil, ii) la legislación en materia de insolvencia, iii) las condiciones de remuneración y de trabajo de la profesión, iv) el tráfico por carretera, v) la responsabilidad profesional, vi) la trata de seres humanos o el tráfico de estupefacientes, y b) que uno o varios Estados miembros no hayan condenado al gestor de transporte o a la empresa de transporte por una infracción penal grave o lo hayan sancionado por una infracción grave de la normativa comunitaria relativa, en particular, a: i) tiempo de conducción y períodos de descanso de los conductores, tiempo de trabajo e instalación y utilización de aparatos de control, ii) peso y dimensiones máximos de los vehículos de transporte en el tráfico internacional, iii) cualificación inicial y formación continua de los conductores, iv) idoneidad para la circulación por carretera de los vehículos de transporte, con inclusión de las inspecciones técnicas obligatorias de los vehículos de motor, v) acceso al mercado del transporte internacional por carretera de mercancías o, según el caso, acceso al mercado de transporte de viajeros por carretera, vi) seguridad del transporte de mercancías peligrosas por carretera, vii) instalación y utilización de limitadores de velocidad en determinadas categorías de vehículos, viii) permiso de conducir, ix) acceso a la profesión, x) transporte de animales $[\ldots]$.

${ }^{60}$ Sobre ello, entre otros: Unai Belintxon Martin, «El dilema en el conflicto del Taxi y el VTC: ¿La desregulación?», en Bitácora Millennium DIPr: Derecho internacional privado, núm. 9, (2019): 1-13. 
No obstante, la cuestión se complica en cierta medida en el concreto caso expuesto, ya que ante la apertura de un foro exorbitante en Francia que no respeta ni el Derecho europeo ni los citados Derechos Humanos para el enjuiciamiento de la causa, nos veríamos en la compleja tesitura de que la calificación de no honorable, o de ausencia de honorabilidad, de la empresa transportista condenada en Francia, no sería tal en el resto de Estados miembros de la UE, por ejemplo España, donde nuestras normas internas aplicables al sector sí respetan el Derecho europeo de aplicación y la no vulneración de los Derechos Humanos a la tutela judicial efectiva y al juez predeterminado por la ley, y en consecuencia, no reconocerán para estos supuestos la sentencia francesa al encontrarnos ante una resolución de carácter claudicante. En efecto, esto supone que el porteador/transportista no nacional francés al que se le condenó en los términos expuestos seguirá ostentando licencia comunitaria y autorización habilitante en el Estado en el cual tiene su nacionalidad y/o domicilio principal. Con lo que nos encontramos ante una doble calificación sobre la legalidad de dicha empresa porteadora para ejercer el comercio de servicios al que se dedica según ejecute $o$ realice transportes que tengan lugar de origen o destino, u origen y destino en Francia y/o pasen por territorio francés, o en el resto de los Estados miembro de la UE que aceptan la legalidad europea y la interpretación jurisprudencial del TJUE y del TEDH.

Conflicto jurídico con fondo político éste de compleja solución que debe resolverse con el fortalecimiento de los principios inspiradores del viejo proyecto de los Estados Unidos de Europa, un espacio común de libertad, seguridad y justicia con plena garantía de los Derechos Humanos.

\section{Derecho social europeo y el sector del transporte aéreo}

\section{Contextualización}

El comercio de la aviación y la aeronáutica internacional han evolucionado y se han desarrollado de forma conjunta y constante permitiendo hablar en la actualidad de un verdadero Derecho aeronáutico. Tal desarrollo evolutivo requirió, tempranamente, de un esfuerzo unificador con la finalidad de reglamentar esta importante actividad comercial. La necesidad de ofrecer una respuesta armonizada en materias tan importantes como la activación del sistema de responsabilidad del transportista/porteador aéreo, la documentación del transporte, las obligaciones de las partes del contrato de transporte aéreo internacional, la determinación de la competencia judicial internacional y de la ley aplicable a las obligaciones contractuales (también las relativas al contrato individual de trabajo), y los tiempos de vuelo, tra- 
bajo y descanso requería un esfuerzo que finalmente encuentra reflejo parcial en el Convenio de Varsovia de 12 de octubre de 1929, modificado en diversas ocasiones y que encuentra hoy su máximo exponente en el Convenio de Montreal de 28 de mayo de $1999{ }^{61}$, pues quedan fuera de su ámbito de aplicación las cuestiones socio-laborales, prevención de riesgos (tiempos de trabajo y descanso ${ }^{62}$ ) y dignidad humana en el trabajo que han sido asumidas para la UE por el/la legislador/a de la Unión ante la ausencia de iniciativa en la esfera internacional que tuviese por finalidad una mayor armonización normativa.

Sin duda el transporte aéreo internacional de mercancías y viajeros constituye el medio de transporte más rápido para las largas distancias. Las características de muchas de las mercancías a transportar requieren de una rápida ejecución del servicio de transporte. No obstante, también debe subrayarse que es uno de los medios de transporte con mayor coste para el demandante del servicio de transporte. En cuanto a las condiciones laborales para la ejecución de los servicios es necesario advertir que éstas son duras al exigir al empleado un cambio de horario continuo (sobre todo en las largas distancias), y el soportar física y psicológicamente la aclimatación ininterrumpida en aquellos vuelos que sobrepasan diversas franjas horarias por razón del lugar de origen y destino del transporte aéreo internacional a ejecutar. Estos son precisamente los transportes regulados por el citado Convenio de Montreal ${ }^{63}$ y por ello es fundamental disponer de un marco jurídico de ordenación socio-laboral, de prevención de riesgos y dignidad humana en el trabajo eficaz, eficiente y garantista que permita un control exhaustivo de los tiempos de vuelo, trabajo y descanso ejecutados por todas las personas empleadas en el sector.

\section{Los tiempos de trabajo y descanso en el sector aéreo. ¿Un sector olvidado o descuidado por la persona legisladora?}

La contienda o conflictividad laboral que enfrentó en 2018 a la empresa porteadora Ryanair y sus empleados y empleadas, en esencia trabajadores y

${ }^{61}$ BOE núm. 122, de 20/05/2004.

${ }^{62}$ Respecto a los tiempos de trabajo y descanso, entre otros: Alonso Pelegrín, Emiliano, García Fernández, Clara, Jerez Del Castillo, Beatriz, Ribes Boigues, María, y Rodríguez Medal, Jaime. Estudio Comparado (UE-28) sobre el Régimen Jurídico Laboral del Transporte por Carretera, Fundación Francisco Corell, Madrid, (2014): 82-95.

${ }^{63}$ Unai Belintxon Martín, «Derecho internacional privado y transporte aéreo: cuestiones de actualidad sobre jurisdicción y ley aplicable», en Petit Lavall, M. ${ }^{\mathrm{a}}$.V., y Puetz, A. (Dirs), El transporte como motor del desarrollo socioeconómico, Marcial Pons, Madrid, (2019): 363-382. 
trabajadoras de cabina y pilotos, permitió el amplio estudio por parte de la doctrina de diversos conflictos de enorme interés para nuestra disciplina del Derecho internacional privado relacionados, por un lado, con la determinación de la competencia judicial internacional ${ }^{64}$ y la concreción del lugar efectivo de trabajo ${ }^{65}$, y por otro, con la determinación de la ley aplicable al contrato de trabajo ${ }^{66}$.

Desde luego la estrategia diseñada por la empleadora para recoger en los propios contratos de trabajo cláusulas atributivas de jurisdicción a los órganos jurisdiccionales irlandeses, junto a acuerdos de elección de ley en favor del ordenamiento jurídico irlandés (insertos en el propio contrato de trabajo y/o en acuerdos $a d$ hoc) ha sido un movimiento jurídico hábil al acompañarse de otra serie de estipulaciones, cláusulas u obligaciones impuestas por parte de la empresa porteadora a las personas empleadas.

Ésta era una práctica generalizada mediante la cual la porteadora aérea contrataba a los empleados y empleadas a través de empresas de trabajo temporal que actuaban reiteradamente como intermediarias para el reclutamiento y provisión del personal al servicio de la compañía ${ }^{67}$. Actuaciones y prácticas que han sembrado claras dudas sobre el posible encubrimiento de cesiones ilegales de trabajadores y trabajadoras. Es decir, la contratación sistemática de pilotos como falsos autónomos y condiciones laborales deplorables ha sido el objeto principal de una denuncia constante por parte de los sindicatos del sector (cuestiones tales como bajas por enfermedad, permisos por maternidad, vacaciones pagadas, edad de jubilación ${ }^{68}$, y retribución del/la trabajador/a en función del número de horas de vuelo sin salario

64 Sobre competencia judicial internacional en procedimientos laborales, entre otros: Olga Fotinopoulou Basurko, «Competencia judicial internacional en pleitos laborales con pluralidad de demandados», en Aranzadi Social, núm. 10, (2008).

65 José Luis Iriarte Ángel, «El contrato de trabajo internacional: algunas cuestiones relacionadas con la competencia judicial internacional», en Cursos de Derecho Internacional y Relaciones Internacionales, Universidad del País Vasco, Tecnos, Madrid, (2001): 119 y ss.

${ }^{66}$ En relación a esta cuestión, entre otros: Paz Menéndez Sebastián, Competencia judicial y ley aplicable al contrato de trabajo con elemento extranjero, Lex Nova, Valladolid, (2006): 60 y ss.

${ }^{67}$ Pilar Juárez Pérez, «El conflicto de Ryanair: una lectura desde el Derecho Internacional Privado», en CDT, Vol.11, núm.1, (marzo 2019): 372-407.

68 Sobre la extinción de la relación contractual laboral de los pilotos una vez cumplidos los 65 años, entre otros estudios pueden verse las reflexiones realizadas por: Rosa M. ${ }^{a}$ Rodríguez Romero, «Nuevas perspectivas en relación con la extinción del contrato laboral de los pilotos de vuelos comerciales una vez cumplida la edad de sesenta y cinco años (a propósito de la STJUE de 5 de julio de 2017, Asunto C-190/16, Caso Fries c. Lufthansa)», en Petit Lavall, M. ${ }^{\mathrm{a} V}$., y Puetz, A. (Dirs.), El Transporte como motor del desarrollo económico, Marcial Pons, Madrid, (2018): 515-533. 
base ni cómputo de la correspondiente antigüedad según los años de servicio realizados ${ }^{69}$ ).

En efecto, es llamativo, y aquí nace la controversia en relación a la determinación de la competencia judicial internacional (aplicable para estos supuestos el RBI bis ${ }^{70}$ ) y la ley rectora del contrato de trabajo (aplicable en este caso el R. Roma I ${ }^{71}$ ), que se imponga por parte del empleador la aplicación de la ley irlandesa (mucho menos favorable para el trabajador que la española por ejemplo) y la competencia judicial internacional de los órganos jurisdiccionales irlandeses ${ }^{72}$. Pero es que además esto viene acompañado de otra serie de exigencias encaminadas a dificultar sobremanera la activación de cualquier acción judicial por parte del empleado o empleada. Téngase en cuenta que con independencia de la residencia habitual del trabajador o trabajadora éstos estaban dados de alta en la Seguridad Social Irlandesa (con los problemas que ello conlleva a la hora de pertenecer al sistema de Seguridad Social de tu residencia habitual, a la hora de requerir asistencia sanitaria o el acceso a productos financieros y/o préstamos hipotecarios y/o personales).

Advertido lo anterior, debe subrayarse igualmente que se ha impuesto de manera generalizada a los trabajadores y trabajadoras la obligación de residir a una distancia no superior a una hora de trayecto desde la base que les ha sido asignada y que suele ser el aeropuerto desde el cual inician su jornada y finalizan ésta. Realidades como ésta, desde luego, restringen el desarrollo vital y personal del/la empleado/a, y según se denuncia por los sindicatos del sector, no tiene una adecuada compensación salarial. Por último, otro dato a tener en consideración es que el trabajo se desempeña a las órdenes de la agencia que intermedia en la contratación del personal bajo la supervisión del personal de Ryanair y a bordo de aeronaves propiedad de la citada transportista.

${ }^{69}$ En relación al nivel salarial de los pilotos y algunos motivos sobre la reducción salarial acaecida en el sector, entre otros: Matías Ginieis, María Victoria Sánchez Rebull y Fernando Campa Planas, «La relación entre el tipo de aerolínea y el nivel de salario de los pi-

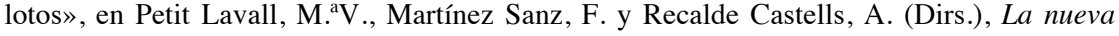
ordenación del mercado de transporte, Marcial Pons, Madrid, (2013): 555-572.

70 Reglamento (UE) n. ${ }^{\circ} 1215 / 2012$ del Parlamento Europeo y del Consejo, de $12 / 12 / 2012$, relativo a la competencia judicial internacional, el reconocimiento y la ejecución de resoluciones judiciales en materia civil y mercantil. DOUE de 20/12/2012, L 351/1.

${ }^{71}$ Reglamento (CE) n. ${ }^{\circ}$ 593/2008 del Parlamento Europeo y del Consejo de 17/06/2008 sobre ley aplicable a las obligaciones contractuales. DOUE L 177/6 de 04/07/2008.

72 Para el estudio de las normas del RBI bis sobre competencia judicial internacional aplicables a este sector, entre otros: Aurora Hernández Rodríguez, «El contrato de transporte aéreo de pasajeros: algunas cuestiones sobre competencia judicial internacional y derecho aplicable», en CDT, vol.3, núm.1, (marzo 2011): 179-194. 
Dicho esto, otra de las denuncias efectuadas por los/las empleados/as tiene que ver con la forma de articular los calendarios de trabajo y la programación de vuelo por parte de la empleadora. La porteadora empleadora de forma generalizada confecciona desde Dublín y entregaba al/la trabajador/a por vía telemática dicha programación sin ningún tipo de interacción directa entre empleado/a y empleador/a. De igual forma, cabe subrayar que tampoco existe una interacción directa o personal en aquellos casos en los que el/la empleador/a activa una acción disciplinaria. Finalmente cabe añadir que el contrato, sus condiciones y demás estipulaciones relacionadas venían a elaborarse en inglés, abonándose incluso los salarios en cuentas de entidades de crédito que el trabajador o la trabajadora debía obligatoriamente abrir en Irlanda coartando o restringiendo los intereses de la persona empleada.

Este conflicto ha situado en el foco central de estudio estas cuestiones de gran relevancia, sin embargo se han desplazado otras no menos importantes como la normativa de ordenación imperante en la UE para normativizar los tiempos de vuelo y descanso de los empleados y empleadas del sector. Ciertamente es llamativa la ausencia de una normativa más nítida para esta cuestión, sobre todo si comparamos la regulación existente sobre ello con la normativa que se encuentra en vigor para el sector del transporte por carretera. Téngase en cuenta que estamos hablando de ciertos conceptos acuñados en la doctrina francesa como el riesgo penal en el Derecho del trabajo, la dignidad humana en el ámbito laboral y la vulneración de los Derechos Humanos por parte de la persona empleadora/transportista ${ }^{73}$.

Las entidades sindicales han subrayado tradicionalmente la importancia de adecuar de forma constante las normas en vigor en la UE sobre limitaciones del tiempo de vuelo, trabajo y descanso. Es ciertamente llamativo que para el sector del transporte por carretera se disponga desde el año 2006 de un Reglamento de aplicación directa, el comentado Reglamento 561/2006, y sin embargo para el sector aéreo se haya permitido a las distintas Agencias Estatales de Seguridad Aérea de los Estados miembros de la UE aplazar la entrada en vigor de la normativa europea sobre limitaciones de tiempos de vuelo, actividad y descanso de forma reiterada hasta casi iniciado el 2018.

Nos referimos al Reglamento 83/2014 ${ }^{74}$ de la Comisión, de 29 de enero de 2014, que modifica el Reglamento (UE) n. ${ }^{\circ} 965 / 2012^{75}$, por el que se es-

73 Parte de la doctrina francesa ya reflexiona sobre la cuestión, entre otros autores: ROBACZEWSKI, Corinne. Le risque pénal en Droit du transsport; L'application du droit pénal du travail dans l'entreprise de transport, Larcier, Bruselas, (2012): 287-303.

${ }^{74}$ DOUE L 28/17 de 31/01/2014.

75 DOUE L 296/1 de 25/10/2012. 
tablecen requisitos técnicos y procedimientos administrativos en relación con las operaciones aéreas en virtud del Reglamento (CE) n. ${ }^{\circ}$ 216/2008 del Parlamento Europeo y del Consejo ${ }^{76}$, que recoge expresamente en su artículo 2 la posibilidad de acogerse a una moratoria en relación a su entrada en vigor hasta el 17 de febrero de 2017 al indicar que [...] los Estados miembros podrán optar por no aplicar las disposiciones del punto ORO.FTL.205 (e) del anexo III del Reglamento (UE) 965/2012 y seguir aplicando las disposiciones nacionales existentes relativas al descanso en vuelo hasta el 17 de febrero de 2017.

Suiza, Dinamarca, Alemania y España se acogieron a tal opción. Un aplazamiento que parece respondía a la presión ejercida por los operadores aéreos con el objetivo de disponer de más tiempo para adaptarse a una regulación cuyo objeto era implantar un mayor control y la mejora de la seguridad aérea mediante normas más restrictivas. En esencia se buscaba reducir los largos periodos o tiempos de vuelo, mejorar las condiciones para la ejecución de los descansos en vuelo y tierra, y posibilitar un mayor control sobre los extensos periodos de actividad (tiempos de vuelo, trabajo, incidencias e imaginarias, y condiciones para la ejecución de todo ello) ${ }^{77}$.

La norma ORO.FTL.205 recogida en el Reglamento 83/2014 es la dedicada a los periodos de actividad de vuelo, una norma que comparte sección entre otras con la 210 (tiempos de vuelo y periodos de actividad), la 220 (actividad partida), 225 (imaginarias y actividades en el aeropuerto), 235 (periodos de descanso), 240 (alimentación) y 245 (registros de la base, de tiempos de vuelo, de periodos de actividad, y periodos de descanso y disfrute personal).

Llama poderosamente la atención que una cuestión de gran calado para la seguridad aérea y para el ámbito de la prevención de riesgos laborales, los Derechos Humanos y la dignidad en el trabajo se trate en Anexos a la norma principal, en concreto en su Anexo III. Da la sensación de que se relega a un segundo plano una cuestión jurídico-laboral relacionada con los Derechos Humanos nuclear tanto para empleador/a y empleados/as como para los usuarios o usuarias, clientes/as o cargadores/as del sector. Tampoco han tenido estas deficiencias un eco doctrinal y/o jurisprudencial suficiente a pesar de ser éste otro de los conflictos que ha aflorado en el asunto Ryanair citado.

76 DOUE L 79/1 de 19/03/2008.

77 Sobre la inspección y el control por parte de la Administración en el sector del transporte, entre otros: Vicenç Aguado I Cudolà, «Las potestades de inspección y sanción en materia de transporte: garantizar el cumplimiento de la legislación, asegurar el buen funcionamiento del sistema», en Menéndez, O. (Dir.), Régimen Jurídico del Transporte Terrestre: Carreteras y Ferrocarril, Tomo II, Aranzadi, Cizur Menor, (2014): 237-287. 
Subrayado lo anterior, es necesario indicar que a pesar de las mejoras incorporadas por las citadas normas ORO.FTL mediante la modificación del Reglamento 952/2012 por el Reglamento 83/2014, la regulación evidencia ciertas carencias que deben corregirse y encauzarse para que pueda materializarse un control más efectivo y eficiente sobre el cumplimiento de la norma europea de aplicación. Desde luego esta ausencia de regulación es muy notable si comparamos este sistema normativo con el actualmente imperante en el sector carretera y que hemos analizado en el epígrafe anterior.

El análisis combinado de las normas ORO.FT.205 (período de actividad de vuelo) y ORO.FT.210 (tiempos de vuelo y períodos de actividad) no permite concluir que para los miembros de la tripulación los periodos de actividad totales en siete días consecutivos serán de 60 horas, 110 horas en el caso de 14 días consecutivos y 190 horas de actividad en el plazo de 28 días consecutivos. Respecto a los tiempos de vuelo máximo, la norma europea viene a establecer un máximo de 100 horas de vuelo en 28 días consecutivos, un máximo de 900 horas de vuelo en un año natural y un máximo de 1000 horas de vuelo en cualquier periodo de 12 meses consecutivos. De la norma expuesta genera cierta inseguridad y tiene una incidencia significativa sobre la prevención de riesgos y los Derechos Humanos la calificación de año natural, un concepto que permite sortear el límite establecido de 1000 horas para el periodo de 12 meses consecutivos. Sin duda esta calificación genera cierta distorsión que debiera de ser corregida ya que el mantenimiento de esa medición de horas máximas vinculadas al año natural y no a los 12 meses consecutivos incrementa la ratio de tiempo de vuelo por mes y permite al operador empresarial o porteador jugar con ello en su propio interés o beneficio.

Es decir, en aplicación de la norma ORO.FT.210.b.3 la división de 1000 horas en 12 meses consecutivos proyecta un resultado o límite máximo de tiempo de vuelo mensual de 83.33 horas. Sin embargo, si el cómputo se realiza en aplicación de la sección b.2 de la misma norma ésta permite que se incremente el límite máximo del tiempo de vuelo que regula la norma anterior al permitir, en aplicación del año natural, que en un periodo de 18 meses el número de horas de vuelo proyecte una suma total de 1800 horas, lo que arroja un tiempo de vuelo máximo mensual de 100 horas. Como advertimos anteriormente, esta doble regulación permite al empleador o empleadora jugar con la activación de uno u otro cómputo según lo que más le pueda beneficiar y en detrimento, a nuestro juicio, de la seguridad con incidencia directa en la prevención de riesgos, en la dignidad en el trabajo, en los Derechos Humanos y en los tiempos de vuelo, trabajo y descanso y disfrute.

En relación a la norma ORO.FTL.235 sobre periodos de descanso cabe advertir que el precepto hace una doble distinción entre aquellos supuestos 
en los que el periodo de descanso diario se toma en la base y para los que su duración no será inferior a 12 horas, de aquellos supuestos en los que el descanso se toma fuera de la base y para los cuales el descanso no será inferior a 10 horas siempre y cuando al menos 8 horas sean de sueño. Esta norma viene acompañada de un concepto indeterminado que genera cierta inseguridad a la hora de referirse a aquellos descansos diarios no inferiores a 12 horas tomados en la base, pues éstos deberán ejecutarse en alojamiento adecuado para el miembro de la tripulación para no vulnerar el Derecho Humano a la dignidad humana en el trabajo.

Efectivamente, no se concretan las características de dicho alojamiento y en consecuencia tal indefinición hace plantearse si se puede entender por alojamiento adecuado y digno un cuarto en el que únicamente se hayan instalado literas para pernoctar, o si dichas instalaciones deben ostentar o no ducha y baño para las necesidades fisiológicas correspondientes, o si sería suficiente una habitación con asientos reclinables aislada. Desde luego llama la atención que no se concrete en la norma tal transcendental cuestión, pues al analizar y comparar la normativa de aplicación a los tiempos de descanso en el sector del transporte por carretera, sí se concretaban las características del vehículo para aquellos casos en los que el empleado o empleada optase por realizar los tiempos de descanso diarios en el camión, exigiéndose que éste debe estar adecuadamente equipado con literas para el correspondiente descanso de la persona conductora (art.8.8 R.561/2006) y calificando lo contrario de vulneración de la dignidad humana en el trabajo y por lo tanto de los Derecho Humanos de la persona trabajadora.

En efecto, cabría completar la redacción de tal norma por el legislador o la legisladora europea para puntualizar las características de una instalación adecuada en base (aeropuerto) y adecuarla a los estándares mínimos en materia de dignidad humana en el trabajo y evitar así la vulneración de este Derecho Humano. En nuestra opinión una instalación óptima para dormir debiera permitir un descanso adecuado en una habitación individual, aislada acústicamente, con temperatura regulable, con ducha y WC y proporcionando instalaciones para comer y beber adecuadamente.

Por último, encontramos otra potencial laguna de regulación criticable en la norma ORO.FTL.245 (sobre registros de la base, tiempos de vuelo, períodos de actividad y períodos de descanso), una vez más cabe señalar que la norma correspondiente para el sector del transporte por carretera es mucho más completa. Esta norma 245 impone para su control por las autoridades la conservación por parte del operador u operadora durante un período de 24 meses de los registros individuales de cada miembro de la tripulación relacionados con: los tiempos de vuelo; el inicio, la duración y el término de cada uno de los períodos de actividad y 
de actividad de vuelo; los periodos de descanso y los días libres de toda actividad; y la base asignada. También impone que se realicen y registren informes sobre períodos de actividad de vuelo extendidos y períodos de descanso reducidos o minorados.

Eso sí, expuesto lo anterior, no se recoge una expresa referencia a la responsabilidad objetiva del empresario porteador o empresa transportista para aquellos casos en los que pudieren cometerse infracciones en relación a los tiempos de vuelo, trabajo y descanso, la responsabilidad social corporativa y la pérdida de honorabilidad de la persona empresaria. Y aquí la norma europea se aleja de lo dispuesto para el sector del transporte por carretera por el artículo 10 del Reglamento 561/2006 y la anteriormente citada jurisprudencia del TJUE que vienen a señalar la responsabilidad objetiva del empleador o empleadora transportista por las infracciones cometidas por él o por cualquiera de sus empleadas y empleados.

En definitiva, todas ellas distorsiones y lagunas de regulación que caben mejorar para garantizar la seguridad aérea y un mayor control del cumplimiento efectivo de los tiempos de vuelo, trabajo y descanso, la dignidad humana en el trabajo y en definitiva los Derechos Humanos en este transcendental sector comercial europeo y extraeuropeo ${ }^{78}$.

\section{Consideración final}

Los Estados Unidos de Europa de los Derechos Humanos requieren de la definitiva consolidación y consagración del proceso de integración para ofrecer con ello respuesta a todos los retos a los que se enfrenta el mundo y Europa en los albores del siglo XXI. Las repuestas y medidas que exigen las nuevas necesidades y retos no pueden descansar única y exclusivamente en los Estados. Nos referimos, en efecto, a los factores de pobreza, inestabilidad financiera, migraciones, desnutrición infantil, cambio climático, vulneraciones sistemáticas de los Derechos Humanos, degradación medioambiental, enfermedades pandémicas, seguridad en el medio de trabajo, y el respeto y la garantía a la dignidad humana en el trabajo o el medio laboral. Sin duda una sociedad de naciones que emerge de los valores y el respeto a los Derechos inalienables de las personas es mayor garantía para una respuesta efectiva a dichos retos.

78 Sobre la fundamental importancia del transporte para nuestra economía, nuestra sociedad y desarrollo interior aunque en referencia expresa al sector por carretera, entre otros estudios puede verse: F. Javier Piñales Leal, Régimen Jurídico del transporte por carretera, Marcial Pons, Madrid, (1993): 32-43. 
El sector del transporte, en este caso aéreo y por carretera, no es ajeno a las vulneraciones de los Derechos Humanos y las medidas de control diseñadas al efecto por el binomio compuesto por el Derecho europeo y el Derecho internacional deben mejorarse y redefinirse con la finalidad de evitar interesadas interpretaciones del Derecho social europeo por parte de los Estados miembros. En efecto, deben evitarse de forma expresa las particulares manifestaciones que en los últimos años efectúan algunos Estados miembros en detrimento de los valores ya consagrados en la UE sobre seguridad jurídica, buena administración de justicia, evitación de procedimientos paralelos y confianza recíproca en seno de la justicia en el propio territorio de la Unión de la libertad, la seguridad y la justicia.

En concreto las instituciones europeas y el TJUE deben ofrecer una respuesta jurídico-normativa contundente a la conflictividad interpretativa y la vulneración del Derecho europeo que el Estado francés abandera o enarbola en particular para el sector del transporte por carretera. No ofrecer respuesta temprana a esta cuestión supondrá el enquistamiento de posturas jurídiconormativas y políticas que debilitan el común proyecto en una era en la que los nacionalismos irredentos deben dejar paso a una Europa de las naciones y las regiones. Nacionalismos que sin embargo no parecen diluirse lo suficiente (cuestión que deja patente la salida definitiva del Reino Unido de la UE materializada en febrero de 2020).

Garantizar la libre prestación de servicios, la libre circulación de personas y el espacio de libertad, seguridad y justicia es clave para el sector del transporte en relación a todos sus aspectos, pero más si cabe aún en relación a la dignidad en el trabajo, el respeto a los Derechos Humanos, la responsabilidad social corporativa, la honorabilidad de la empresa porteadora, y el Derecho social europeo. No obstante, es importante señalar que la garantía de los Derechos Humanos es una vía bidireccional y a dos carriles (empresa-persona empleada; persona empleada-empresa; Estado-empresa; empresa-Estado).

Respecto al binomio objeto de estudio, sector aéreo y sector carretera, asombra o por lo menos es llamativa que la normativa de aplicación a esta cuestión en el sector aéreo sea tratada en un Anexo a la norma principal y que contenga normas sobre tiempos de vuelo, trabajo y descanso indefinidas que permitan al/la operador/a empresarial decidir el cómputo a aplicar para limitar o ampliar el número de horas mensuales de tiempo de vuelo máximo. Esta situación hay que revertirla cuanto antes legislativamente. Por otro lado, y en relación ya al transporte por carretera, es igualmente llamativo que ni las instituciones de la UE ni el resto del Estados miembros de la UE se pronuncien acerca de la flagrante vulneración del Derecho europeo (artículo 8.8 del Reglamento (CE) 561/2006 dedicado 
la prevención de riesgos laborales y a la dignidad humana en el trabajo - descanso en la cabina habilitada al efecto en el vehículo-) por parte de Francia. Vulneración que como expusimos recoge expresamente este país en su ordenamiento jurídico nacional.

Finalmente, en relación a las exorbitantes competencias jurisdiccionales francesas y criterios de atribución con base en un concepto de imperialismo jurídico inaceptable, deben subrayarse y recordarse las garantías, en cuanto al Derecho Humano a la tutela judicial efectiva en un sentido amplio, que el CEDH y el CEDF ofrecen y garantizan mediante la interpretación de sus normas por parte del TEDH y el TJUE. La reversión de esta situación legislativa indecorosa e inaceptable debe venir de la mano de la presión que los distintos Estados miembros de la UE, las instituciones de la UE y los órganos jurisdiccionales de todos ellos puedan ejercer frente al Estado francés mediante la firmeza en la calificación como claudicantes en sede de reconocimiento y ejecución de las resoluciones judiciales emitidas para el sector del transporte por carretera por los órganos jurisdiccionales franceses. Sin duda, Alemania y Francia vertebran, más si cabe tras la espantada del Reino Unido, la UE, pero esto no es óbice para que las instituciones europeas y el resto de Estados miembro del proyecto común exijan a ambas dos, y particularmente a Francia, la vuelta a la legalidad europea.

\section{Sobre el autor}

Unai Belintxon es Doctor en Derecho (Derecho internacional privado) por la Universidad del País Vasco (EHU-UPV), Máster en Derecho de Empresa por la Universidad de Deusto; Máster en Integración Política y Económica en la Unión Europea por la Universidad del País Vasco, EHU-UPV (acceso doctorado), y Máster de Acceso a la Abogacía por el Colegio de Abogados de Gipuzkoa. Es profesor contratado doctor de la Universidad Pública de Navarra (UPNA) e investigador del Instituto de Gobernanza Democrática (Globernance) y del Instituto I-Communitas. Ha realizado estancias como profesor investigador en diversas universidades, destacando el Instituto Suizo de Derecho Comparado. Sus líneas de investigación engloban materias como Derecho internacional privado, Derecho del transporte internacional, Derecho del deporte y litigación transfronteriza, y Derechos humanos y negocios. Sus últimos libros son Derecho europeo y transporte internacional por carretera (Aranzadi-Thomson Reuters 2015), La necesaria adecuación de la legislación vasca del transporte a la dimensión transfronteriza (Aranzadi-Thomson Reuters 2018), y Cooperación, Seguro y Actividades deportivas transfronterizas. Un estudio jurídico (Aranzadi-Thomson Reuters 2018). https://orcid.org/0000-0001-7512-3839. 


\begin{abstract}
About the author
Unai Belintxon is a $\mathrm{PhD}$ in Law (Private International Law) at the University of the Basque Country (EHU-UPV), Master in Business Law at the University of Deusto, Master in Political and Economic Integration in the European Union at the University of the Basque Country, EHU-UPV (to Access of PHD), and Master in Law and Legal Practice at the Gipuzkoa Bar Association. Teaching-researcher at the Public University of Navarra (UPNA) and associated researcher at the Institute of Democratic Governance (Globernance) and the Institute I-Communitas. He has been a visiting fellow at several universities, including the Institut Suisse de Droit Comparé. His main work-lines cover areas such as private international law, international transport law, sport law and cross border litigation, and human rights and business. His last works are Derecho europeo y transporte internacional por carretera (Aranzadi-Thomson Reuters 2015), La necesaria adecuación de la legislación vasca del transporte a la dimensión transfronteriza (Aranzadi-Thomson Reuters 2018), and Cooperación, Seguro y Actividades deportivas transfronterizas. Un estudio jurídico (Aranzadi-Thomson Reuters 2018). https://orcid.org/0000-0001-7512-383.
\end{abstract}




\section{Derechos de autor}

Los derechos de autor (para la distribución, comunicación pública, reproducción e inclusión en bases de datos de indexación y repositorios institucionales) de esta publicación (Cuadernos Europeos de Deusto, CED) pertenecen a la editorial Universidad de Deusto. El acceso al contenido digital de cualquier número de Cuadernos Europeos de Deusto es gratuito inmediatamente después de su publicación. Los trabajos podrán leerse, descargarse, copiar y difundir en cualquier medio sin fines comerciales y según lo previsto por la ley; sin la previa autorización de la Editorial (Universidad de Deusto) o el autor. Así mismo, los trabajos editados en CED pueden ser publicados con posterioridad en otros medios o revistas, siempre que el autor indique con claridad y en la primera nota a pie de página que el trabajo se publicó por primera vez en CED, con indicación del número, año, páginas y DOI (si procede). Cualquier otro uso de su contenido en cualquier medio o formato, ahora conocido o desarrollado en el futuro, requiere el permiso previo por escrito del titular de los derechos de autor.

\section{Copyright}

Copyright (for distribution, public communication, reproduction and inclusion in indexation databases and institutional repositories) of this publication (Cuadernos Europeos de Deusto, CED) belongs to the publisher University of Deusto. Access to the digital content of any Issue of Cuadernos Europeos de Deusto is free upon its publication. The content can be read, downloaded, copied, and distributed freely in any medium only for non-commercial purposes and in accordance with any applicable copyright legislation, without prior permission from the copyright holder (University of Deusto) or the author. Thus, the content of CED can be subsequently published in other media or journals, as long as the author clearly indicates in the first footnote that the work was published in CED for the first time, indicating the Issue number, year, pages, and DOI (if applicable). Any other use of its content in any medium or format, now known or developed in the future, requires prior written permission of the copyright holder. 